\title{
The forming process of Fiumicino
}

\author{
Giuseppe Strappa, Marta Crognale
}

Dipartimento di Architettura e Progetto. Facoltà di Architettura.

Università degli Studi "Sapienza" di Roma. Roma, Italy

E-mail: gstrappa@yahoo.com,marta.crognale@libero.it

\begin{abstract}
This work, carried out within the Lettura e Progetto (Lpa) Laboratory of "Sapienza", University of Rome, and based on the "processual" method, proposes the regeneration, through the reading and interpretation of the forming process, of the urban settlement of Fiumicino, on the east coast of Rome. The area was formed by a set of fragmented interventions developed in different phases, with heterogeneous destinations and, apparently, no relation of necessity between them. The site appears mainly linked to the development of illegal buildings that date back to the second postwar period. However, a deeper analysis based on the reading and interpretation of the character of the building fabric, shows the existence of a clear relation of historical continuity between the today town and the territorial structures developed starting from the ancient city of Portus. Through this reading emerges the plan of a town connected to the activities of Porto Canale (Channel Port) in function since XVI Century. From the analysis of the historical cartography appears as a matrix route based on the continuation of the ancient via Portuense was formed in time and developed on the building routes that have resulted. We propose a hypothesis of regeneration in the existing fabric through the densification of routes at higher urban vocation. We believe that this is a remarkable case study that exemplifies the potential formation of local identity at the edge of the metropolis as over time the area has developed a complex structure, connected to port activities, that is now forming its own urban character and individuality, so that recently it was constituted in autonomous municipality.
\end{abstract}

Keywords: Fiumicino, Portuense, forming process.

\section{Topic}

The inhabited area of Fiumicino, settled on the eastern coast of Rome in relatively recent times, and for long considered a remote, peripherical area of the city of Rome, recently become an autonomous municipality independent of the Capital, constitutes a major case study showing how the outer fringe of the great Italian cities can be considered historical territory.

The Municipality of Rome had already begun in 1976/77 an operation for the recognition and perimeter survey of areas that the current PRG classified as "agricultural, of expansion or industrial" and which were, as a matter of fact, characterized by the presence of many spontaneous buildings, often illegal, with predominantly residential purpose. These areas were delimited and subjected to variation in urban destination and 74 abusive settlements were identified, including Fiumicino. This operation has highlighted the specificity of these areas, so as to identify definite urban planning tools (' $\mathrm{O}$ ' zone variants) for their urban regeneration.

In particular, the area of Fiumicino showed problems so peculiar and dissimilar from those of the Capital to assume the necessity of a separate administration. On 4 April 1992, with a referendum, the Fiumicino Municipality officially formed. On that date Fiumicino acquired administrative autonomy, but lacking 
its own urban planning instrument. The PRG, the General Urban Planning of Rome (approved in 1965 and subject to numerous variations, where the Fiumicino area is defined as the 14th district of Rome) remains still effective at present for the Fiumicino area. On 31st December 2016, 79.806 people reside in the territory of the Municipality, which has an extension of 22,000 hectares (about 8,000 are in Fiumicino centre). Aside from the area known as Isola Sacra with 32,000 inhabitants, the settlement of Fiumicino centre is the most populated among the entire communal territory ones.

\section{Method}

This area is currently being studied by the Lpa (Reading and Design of Architecture) laboratory, in continuity with researches on the eastern outskirts of Rome, already being published (Strappa, 2012).

The steps of this study are briefly illustrated below:

1. Reconstruction of the formation process based on historical cartography, IGM mapping (Military Geographic Institute), photogrammetric maps, cadastral plans.

2. Identification of pathways structure and land subdivisions that prove to be, as always, the most conservative elements of the fabric.

3. Analysis of the aggregative organism based on the recognition of fabric elements and their characters: routes and poles; edilizia di base and edilizia speciale. It should be noted that the edilizia (an abstract term) extensively employed in Italian architectural literature and often translated simply as building (a concrete term), refers in general to the activities related to the evolution of the city and its built result (Ieva, 2014). As such does not have a corresponding English term. An old translation problem never really solved that caused many misunderstandings. In the field of Urban Morphology, it should indicate, in our opinion, the set of components, organized by routes, that contribute to the formation of the fabric: the building and the ground on which it is built. In particular, refererring to the building plot, the term edilizia corresponds to the building proper and the pertinent area to which it is typologically inseparably linked.

4. Identification of the potentials transformation of the aggregative organism based on the characters recognized in the fabric.

Here we therefore propose a reconstruction of the building fabric, by the means of recognizing a still operating process of innovation/renewal.

The analysis, based on the "processual" method, clarifies the nature of the formation of Fiumicino and the persistence over the years of its local identity despite the fact that the central nucleus played the role of an extended residual area for the provision of "low added value" services for the capital, since the unity of Italy (1861).

\section{Analysis}

Today Fiumicino appears at a first as a hybrid place: a modest residential fabric with a tiny XIX Century historical centre, influenced by the presence of a Tiber channel and by the proximity of the Leonardo Da Vinci International Airport. The most prevalent activities are small scale naval shipbuilding, fishing sorting and limited local tourism. The building fabric looks like a fragmentary set of heterogeneous constructions, built mainly in the post-war period and without apparent connection between the single parts. The current system of settlements does not derive its origin either from the restructuring works that affected the area of Isola Sacra around the 1920s, nor from the planning actions of the Rome Municipality which has always considered Fiumicino a border site with bulky functions (countryside and industrial settlements). The only Fiumicino area that has been considered by zoning plans, by the way never fully realized, was Fiumicino Nord, intended by a Detailed Plan (Piano Particolareggiato) of 1931, to host residential buildings both for the locals and for the roman summer vacationers.

However, a more in-depth analysis focused on reading and interpreting the forming characters of the building fabric shows the existence of a clear historical relationship 


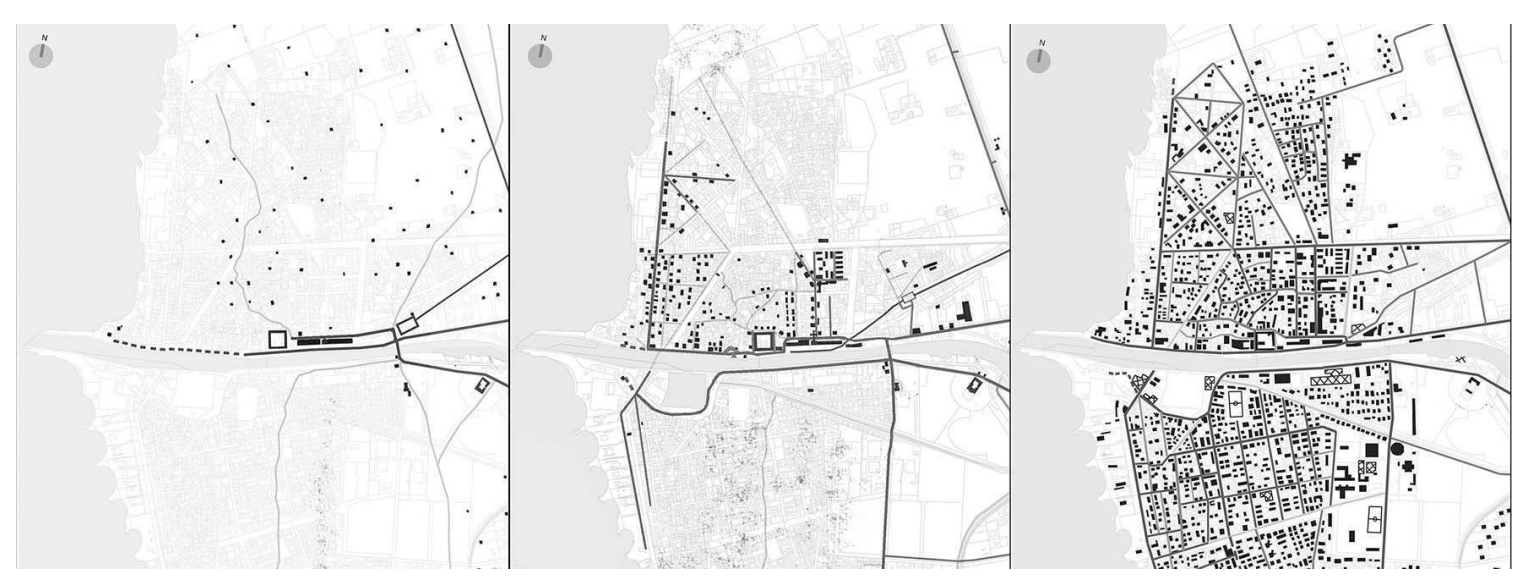

Figure 1.

Reconstruction, on territorial scale, of the forming process of Fiumicino Centro on IGM cartographic base, respectively in the years $1880,1931,1989$.

between the present city and its territorial structure. The nature of a port city clearly emerges, related to the ancient Roman harbour built by Emperor Claudius and to the canal dock, operating since the Sixteenth century. From the analysis of historical cartography, it is evident that the historical small nucleus of Fiumicino has been formed along a matrix route, the current Torre Clementina route, extension of the ancient Via Portuense, and the neoclassical intervention of Giuseppe Valadier (1823-1827) at the same along the matrix route of Via Torre Clementina aimed at the construction of housing and services for the locals, is the first planning attempt and founding act for the ancient seaside village.

The analysis carried out at this stage also shows the presence of a railway line (inaugurated in 1878) connecting Rome, located near the Portuense route and ending in the area in front of the Borgo Valadier.

Through this study, carried out on urban scale and subsequently on a fabric scale, it was possible to reconstruct the formation process of Fiumicino and to interpret the role of the single physical elements structuring the contemporary settlement: streets, squares, buildings, pertinent areas and their mutual relationship.

On an urban scale, the comparison between the cadastral maps and the IGM maps explains the close link between the form of the territory and the settlements intentions, highlighted by the hierarchization of routes and land partition in the area between via Giovanni
Battista Grassi and via della Foce Micina (Strappa, 2012). Fiumicino's contemporary central nucleus, strongly characterized by the apparently non-hierarchized presence of spontaneous constructions, is settled behind the Borgo Valadier along two spontaneous matrix pathways (Via Giovanni Battista Grassi and Via delle Scuole), on which residential buildings were assigned. A fourth planned matrix route was also formed along Via Del Serbatoio, as a result of new constructions works carried out between 1954 and 1989. The real role of these urban axe is not evident to a superficial reading of the fabric, also because of the presence of Via Clementina along the channel to which is usually attributed a centralizing character.

\section{Interpretation}

In the belief that the same principle found in historical centres is to be found in the suburbs and that, more generally, the built landscape is the provisional outcome of a modification in progress (Strappa, 2016), it has been made an attempt to read in the urban reality of Fiumicino the transformations of a processes still in progress.

The reading of the urban fabric carried through the cadastral mosaic of the individual buildings and the reconstruction of the building ground floor plans, carried out along the matrix routes and for individual plots, allowed to recompose the structure of the edilizia part of the fabric and to make the hierarchy of the 


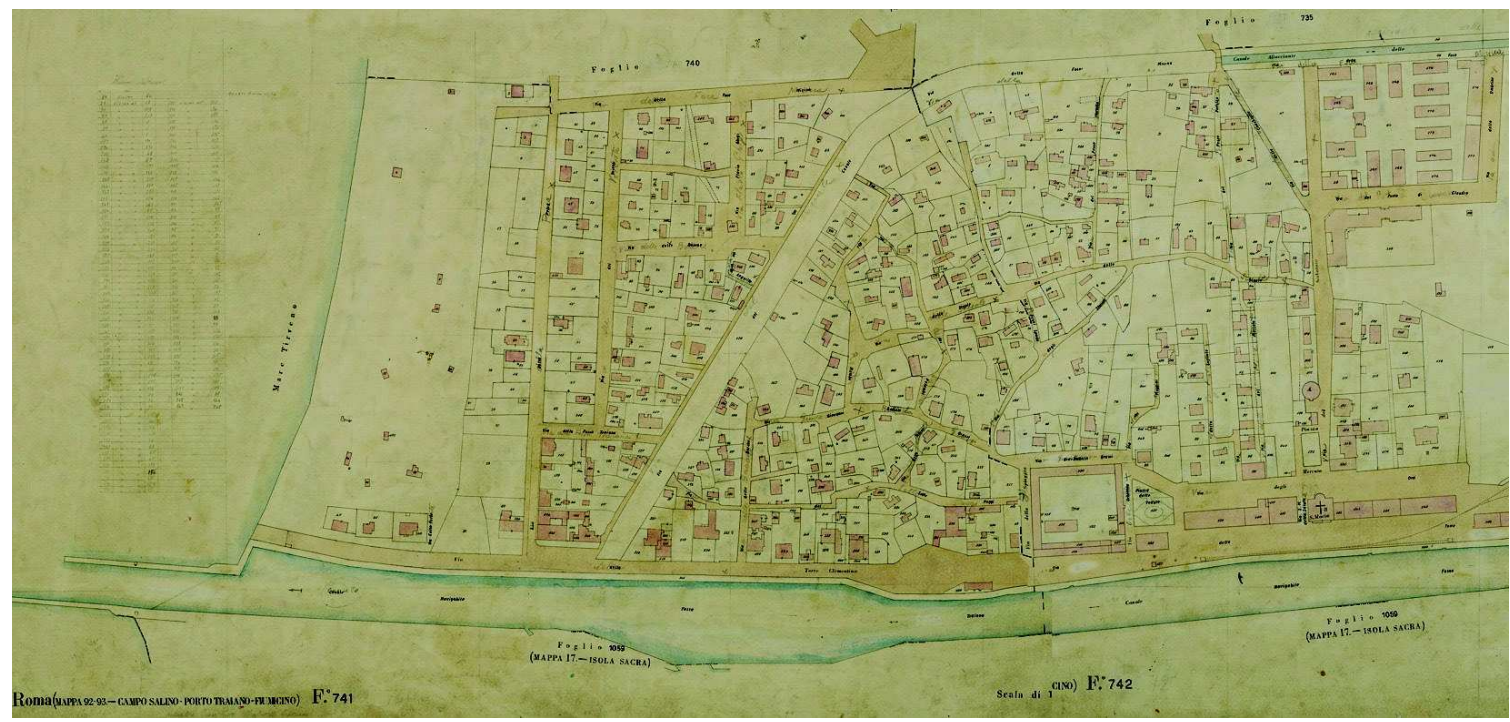

Figure 2.

\section{Cadastral layout, 1965.}

paths explicit within the forming process the settlement. The urban sprawl, largely based on small single-family residential buildings, prevented the constitution of poles, public spaces and continuity of housing facades that would have contributed to a legible urban unity. Although it is legible the presence of a basic dimension of residential spaces that is approximately related to that of the elementary cell, the types of buildings employed seem far from being homogeneous and perhaps derive from the specific cultural area of origin of the builders-dwellers or, in the case of multi-family buildings, from the extemporaneous choices of small building firms.

On the routes of spontaneous origin, Via Giovanni Battista Grassi and Via delle Scuole, we find the recurrent type of the single and multifamily isolated house, located orthogonally to the road and characterized by a private garden. On the matrix route of territorial origin of via Torre Clementina, especially in the area of the buildings designed by Giuseppe Valadier, we find the in linea type, multi-storey buildings characterized by the aggregation of single flats served by a common staircase.

These observations suggest some criteria for restructuring the fabric. In fact we can assume as possible a process of partial recasting of building units along the main routes, leaving current building types in the most "unloaded" paths.
The goal is to provide guidance not only for the development of simple and rational solutions for the new Fiumicino, but also to identify a suitable urban form fitting with the forming process and meeting the expectations of the inhabitants

Considering the feasibility of the hypothesis, we should underline the courageous choice of the municipal administration at the beginning of administrative autonomy (1992), to have preferred not to program a new urban planning scheme in the traditional sense. The connection between the design of Fiumicino's physical form and the need of a principle of citizenship has been captured in the unique historical moment of rethinking of the city.

Since it was not a problem of new expantion but the construction of a political and urban identity, the administration has decided to devote more attention to those spontaneous residential settlements that prevalently dominate the municipal territory and to intervene in a punctual and operational way on these areas by promoting the idea that the project and its implementation were a result indicated time after time by the requirements of the contingencies and not by a long term plan.

Applying a moratorium on the current plan, the Rome PRG, the administration suspended the perenniality of its directions and devoted itself to the design "from below" of the new 

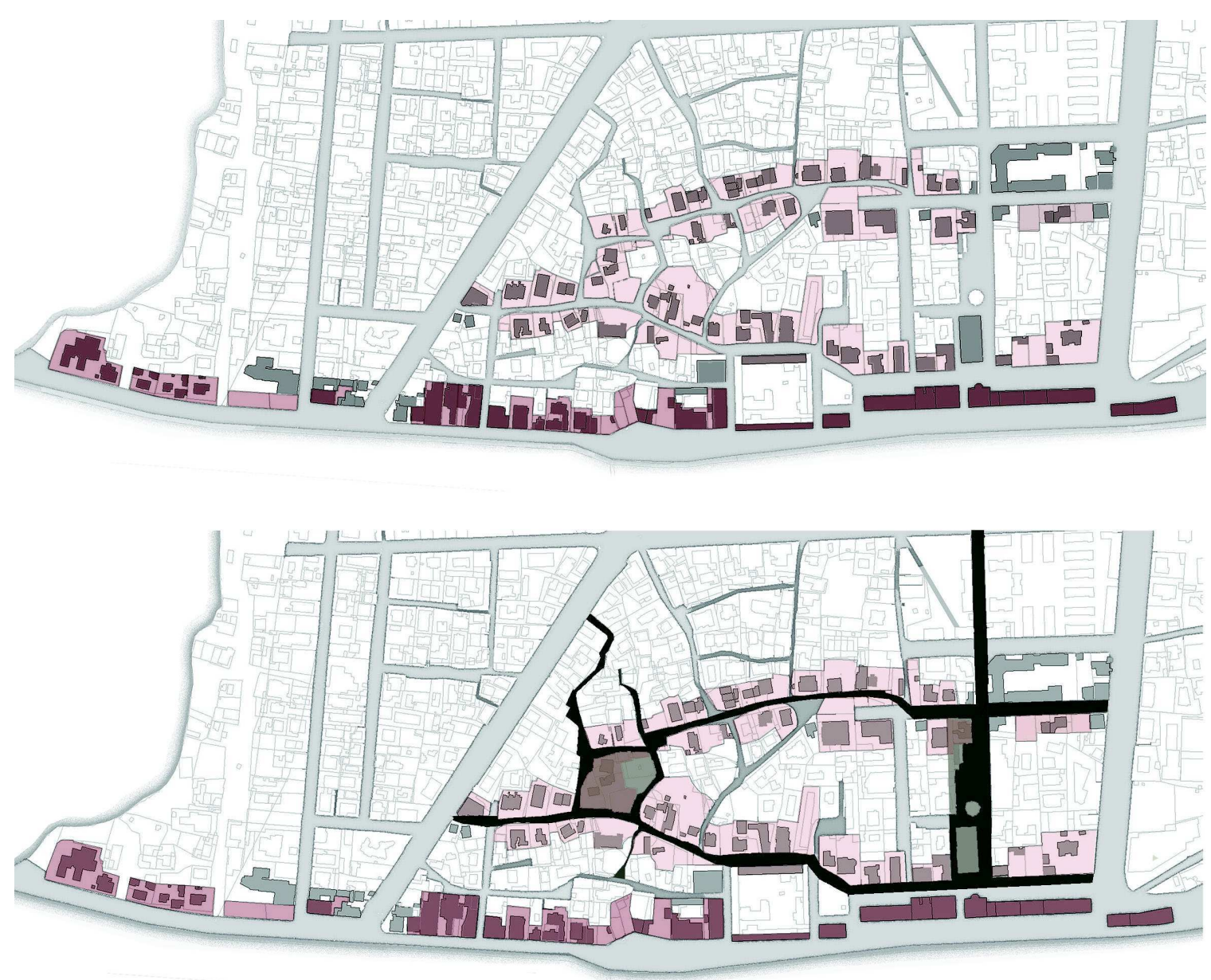

Figure 3.

Analysis of Fiumicino urban fabric on a cadastral basis (Map Extract, 2015). Above: Study of urban morphology and building warpage. Identification of the pertinent strips on the matrix routes of spontaneous origin of Via delle Scuole and Via Giovanni Battista Grassi and the matrix route of territorial origin of via della Torre Clementina. On the routes of Via delle Scuole and via Giovanni Battista Grassi can be found the type of the single and multi-family isolated house, located orthogonally to the street and characterized by a private garden; On the matrix route of territorial origin of via Torre Clementina can be found the type of the multi-storey building with apartments having common staircases. Below: Analysis the Fiumicino Centro building fabric. Formation of urban poles.

community indicating territories and areas where to intervene. Important contributions to this politic were those of Alessandro Anselmi for the construction of the current Isolato Stazione and the new Municipality headquarters, of Carlo Aymonino for the project Porta dei Porti (the new railway exchange junction) and Luca de Merich for the preparation of the Detailed Regeneration Plan Of Fiumicino North.

This happy intuition, as well as the single project attempts, did not end in a unitary project for Fiumicino. In spite the attention immediately addressed, with a practical approach, to the spontaneous settlements and the zoning directions across the entire territory was suspended, since a strategic planning of "vast area", lacking a morphological in-depth, has oriented the interventions towards the construction of special buildings isolated on public property lots, without any relation of necessity to the fabric and lacking the unitary character deriving from a real specialization process.

\section{Densification hypothesis}

The problem of drawing operating consequences from the previous considerations is not simple. 


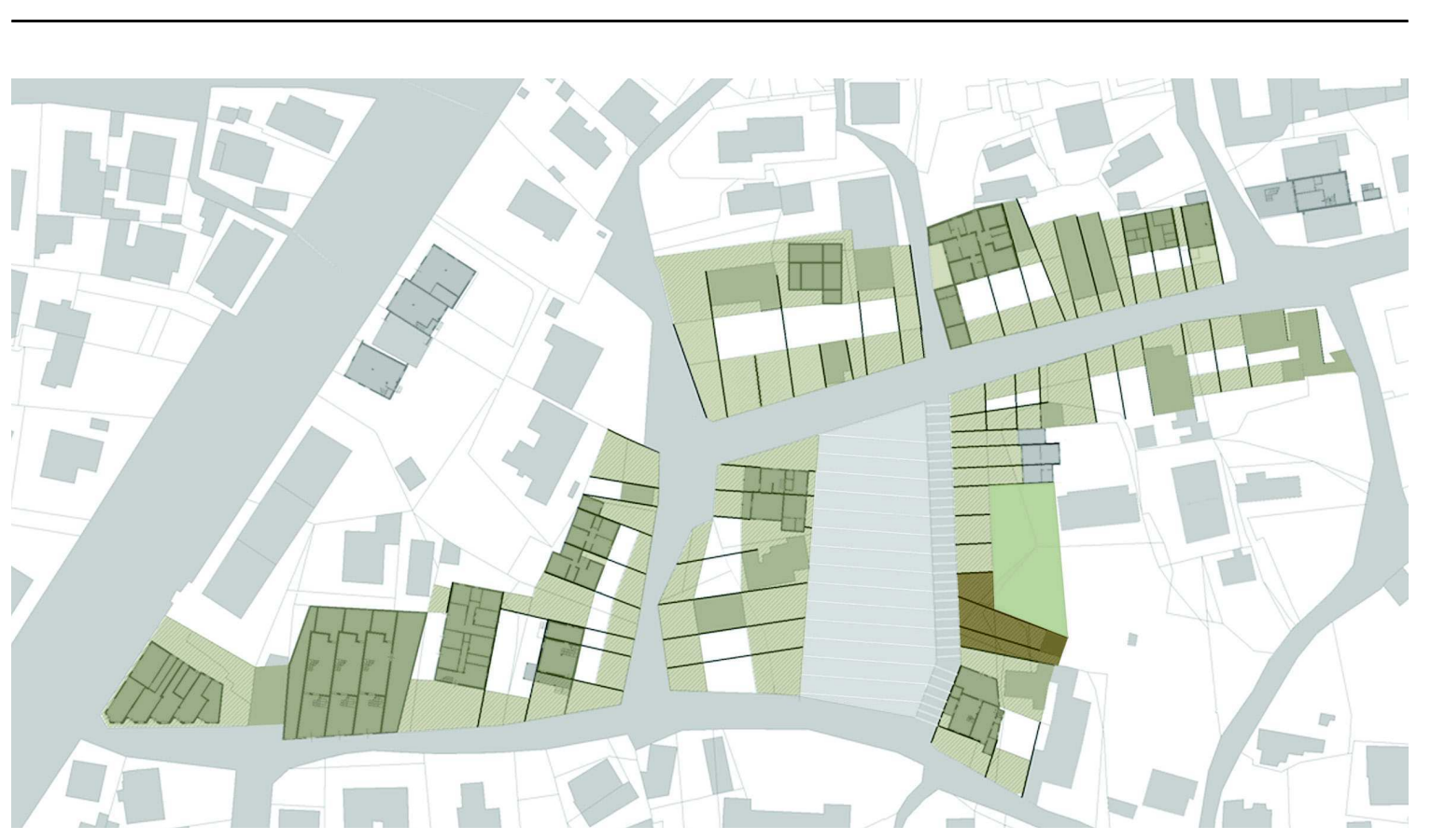

Figure 4.

Densification proposal of the spontaneous urban fabric on via delle Scuole. Reconstruction of the structure of the blocks on the matrix routes of spontaneous origin by recasting the fabric by building the pertinent areas of the housing units and by the construction of passages and common yards within the buildings linearly arranged on the route. No demolition of any existing building is expected. It is foreseen the formation of a new square and special housing in the polar area identified by the analysis of the building fabric.

It is clear that, to transform the actual serial structure of single plots and isolated buildings in a true urban fabric, it is necessary to densify constructions on matrix routes and specialize building at the poles, to increase the supply of services, currently insufficient.

We must deal, however, with the general directions of the old city plan, at present still in force, which include in this area:

- Conservation of existing lots and related areas;

- Completion of partially built lots by repeating the types of buildings used.

- New construction, on free lots, of commercial buildings and services without any analysis of their role.

- As a 'B-completion' area of PRG it is not necessary to satisfy all the standards required by the current regulations (the parameter can be lowered by $50 \%$ ).

- In line with the requirements of the previous 1965 PRG of Rome, which classified some parts of the area we are considering as agricultural, the requirements of some standards can be accomplished in other areas of municipal territory.
- The Detailed Plan of Fiumicino centre merely confirms the existing urban layout on the territory

As a result of these conditions, the proposals that derive from the reading and critical interpretation of the fabric are these that follow:

- If the areas of appurtenance of the buildings that are on the spontaneous matrix pathways were built in order to fix the existing building fabric, and if clogged buildings were to be demolished, there would be no incongruity with the standard criteria of volume conservation, bearing in mind that any porch connection would not increase the cubic capacity. It seems reasonable, however, to propose the granting, with new interventions of recasting of the urban fabric, of an increase in cubic capacity as an incentive for the realization.

- Special buildings and public spaces should be constructed in pole areas. In addition to their specific function, these interventions would increase the standard ratio of standard/mq standard/population

- The choice of densification will lead to the 

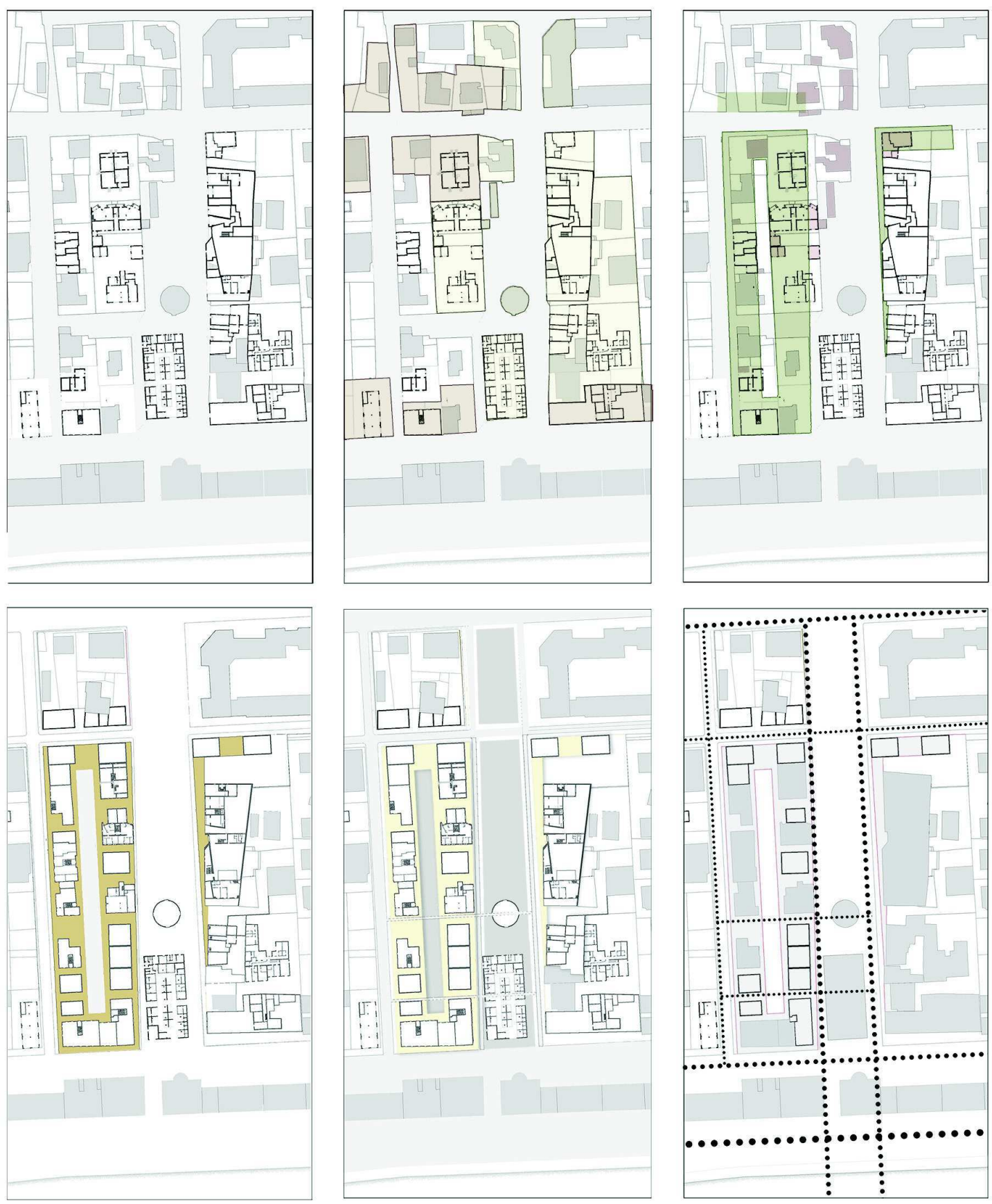

Figure 5.

Densification proposal of urban fabric and formation of a new square on via del Serbatoio (market area). The design includes the preservation of the existing communal market, the replacement of some residential blocks located on the new central square and the recasting of the residential ones located on via del Serbatoio. Existing and newly constructed buildings are connected by the construction of a perimeter gallery within the new block. The last image highlights the paths and routes system and their hierarchy.

construction of arcades, passages, common courts within the buildings, etc. Arranged linearly on the matrix paths. These elements can also be inserted into standard 'definition'.

- Enlargement of the roadway.
With the design in progress we should prove, from a regulatory point of view:

- That densification operations do not increase the volume (in a normative sense) of buildings (especially residential) 
- That the surface reserved to the standards (services and public spaces) could increase. Currently they were calculated at $50 \%$ and part of this $50 \%$ was found outside the Fiumicino centre area.

\section{Normative aspect}

The Fiumicino Centre's Detailed Executive Plan (Piano Particolareggiato Esecutivo or PPE) was adopted in 2002 and, as it has not been approved within 5 years of its adoption as established by law, it has since been considered decayed. As long as the instructions of the detailed plan are not in force, the General Plan PRGs apply. It was, however, a very conservative PPE, who took note of the situation and tried simply to adapt it to the official rules. As it has been attempted to demonstrate, the area we are considering would need, on the contrary, a substantial work of regeneration.

However, although the analysis of the reasons that led to the Fiumicino settlement to be in a marginal condition and the study of the fabric characters may lead to clear operational indications, the problem arises from a planning point of view considering the instruments that can guarantee the real feasibility of the new planned transformation process.

Considering the central role of edilizia di base as a unifying factor for the future transformation, it should be considered that the notion of density includes, in this case, not only the ratio between the number of inhabitants expected (and hence the housing volumes built) and the surface, but the idea of urban concentration expressed by the continuity of built volumes and surfaces including the organization of common pathways and spaces. The reference model is the multi-familiar and continuous fabric of the Italian city, model from which the proposed corrections result. (Marzot, 2012).

The application of this concept is topical, to the point it can become a central element within the process of transformation of Fiumicino.

Instruments are therefore the recasting of the built matter and the densification of the fabric along the matrix paths both spontaneous and planned, as well as the specialisation of poles.
The aim is to direct the process of demographic increase in order to avoid the spreading of it outside the inhabited centre (an important aim of densification is to give a direction to urban growth by avoiding new territory consumption and concentrating the offer of new housing).

If the interventions of recasting and densification of the urban fabric -intended both to improve housing conditions and to develop the identity of the site - would be considered as "public interest" and therefore as necessary for the inhabitants, as the provision of services and works for primary urbanization, the particular relationship between public administrations and private individuals could be used for the implementation of the plan, using the instrument of "sub-funds", urban sectors to be submitted to Convention between the administration and private owners. The administration would so acquire the areas needed for the implementation of the interventions envisaged and would at the same time recognize to the owners (reunited in consortium) effective rights on the soils and buildings, a new real right proportional to the areas originally owned.

The urban planning tool to be used, according to current legislation, should be the Integrated Intervention Program (or PII) provided by Regional Law no. 22/1997, but only on the territory of municipalities with an approved general urban planning instrument and may affect both public and/or private buildings.

Its realization can also be achieved through the partnership of public and/or private subjects, with the respective contribution of financial resources.

The PII can also be used '.... in order to allow the municipal administration to modify the PRG's directions.'

The PII consist of (Article 2) a project of major public interest characterized by the presence of a multiplicity of functions, from the integration of different types, 'including the urbanization works and the infrastructures necessary to ensure the completeness and full functionality of the 'Intervention itself, and of such dimensions as to affect the reorganization of the urban fabric.'

The rules contained in the law (Article 7) also apply to urban recovery programs as 
defined by Article 11 of Legislative Decree 398/1993.

The areas of intervention must be delimitated as 'sub-funds' (which may be either public or of private initiative), landowners must gather in consortiums (with the consent of at least $75 \%$ of the participants) and proceed together with the realization of the works.

If the initiative is declared of public utility, even with the obvious political problems the operation could raise, it would be imperative for the citizens to participate.

However, the inhabitants would be encouraged to participate because the proposed project would guarantee not only the same share of property previously owned but also a bonus in the increase of the living area, an increase in public spaces and facilities (services, shops, parking lots, etc. ), and, in general, a progress in the quality of life.

\section{Conclusions}

The analysis is still under development and the proposal of a densification process, here presented as a conclusion, is in fact still a hypothesis whose limit lies in the private property partitioning. The maintenance of land divisions can be the main difficulty to the implementation of the project. As mentioned above, however, some technical and legal instruments are available which, if properly studied and applied, can allow the formation of an organic tissue to replace the existing urban sprawl. Avoiding to propose the cancellation of any real rights on soils and buildings, we can still assume the concrete feasibility of the proposals.

The research work has not yet been completed but we believe that the kind of intervention hypothesized, if accepted by the Municipality, could contribute to the "processual" construction of a New Fiumicino, obtained from a real regeneration of its centre.

\section{References}

Strappa G. (2016), L'architettura come organismo e processo, in P. Gregory (a cura di) Nuovo realismo/postmodernismo. Dibattito aperto tra architettura e filosofia (Officina, Roma)

Strappa P, Carlotti P., Camiz A. (2016) Urban Morphology and Historical Fabrics. Contemporary design of small towns in Latium - Morfologia urbana e tessuti storici. Il progetto contemporaneo dei centri minori del Lazio, (Gangemi, Roma 2016)

Nardi A. (2015), Fiumicino da pagus a città. (Edizioni Pragmata, Roma)

Ieva, M. (2014), Voce "Edilizia" - http://www. wikitecnica.com

Strappa G. (2014), L'architettura come processo. Il mondo plastico murario in divenire, (Franco Angeli, Milano)

Marzot, N. (2012), Il concetto di densità nel progetto urbano contemporaneo, in Disegnare la città. Urbanistica e architettura in Italia nel novecento: appunti da un ciclo di conferenze (SATE Industria grafica. Ferrara), 130-131

Strappa G., editor (2012), Studi sulla periferia est di Roma, (Franco Angeli, Milano)

AA.VV. (2000), Fiumicino tra cielo e mare. Una storia da vedere. (Publidea '95 srl, Ostia Antica-Roma)

Albano, A. (1998), Per una città gradevole, in Controspazio n. 3/98 (Gangemi Editore, Roma)

Mannucci V. (1995), Atlante di Ostia antica. (Edizioni Marsilio, Venezia)

Bastianelli A., D'Andrea E. (1990), Fiumicino nella storia. (Lito Service di P. Fiorani, Roma)

De Rossi G.B. (1984), Le torri costiere del Lazio, (Newton Compton Edizioni, Roma)

D’Andrea E., Perna Ruggiero E. (1989), Fiumicino Progetto a perdere. (Lito Service di P. Fiorani, Roma)

Frutaz A.P. (1972), Le carte del Lazio. (Istituto di studi romani, Roma)

Ciano, A. (1936), Il Porto Urbano di Roma. (Soc. Tipo-Litografica Ligure, Genova)

Montemaggiori A. (1933), Il piano regolatore di Roma e delle borgate marine: Ostia-mare e Fiumicino: leggi e norme di attuazione. (Stamperia Reale, Roma)

Nibby A. (1848), Analisi storico topografica antiquaria della carta dei dintorni di Roma. (Tipografia delle Belle Arti. Roma) 
Battista Rasi G. (1826), Sul porto Romano di Ostia e Fiumicino. (Tipografia Contedini, Roma) 